\title{
Mass Spectrometric Observations on Reactions of Excited Ions in Carbon Disulfide and some Aromatic Compounds*
}

\author{
By Arnim Henglein \\ Radiation Research Laboratories, Mellon Institute, Pittsburgh, Pa., USA \\ and Hahn-Meitner-Institut für Kernforschung, Berlin-Wannsee, Germany \\ (Z. Naturforschg. 17 a, 37-43 [1962]; eingegangen am 24. Oktober 1961)
}

\begin{abstract}
Reactions have been observed between excited ions of carbon disulfide and carbon disulfide, water, iodine and ethylene. The ions $\mathrm{CS}_{3}{ }^{+}, \mathrm{C}_{2} \mathrm{~S}_{2}^{+}, \mathrm{C}_{2} \mathrm{~S}_{3}{ }^{+}, \mathrm{H}_{2} \mathrm{OS}^{+}, \mathrm{CSI}^{+}, \mathrm{SI}^{+}, \mathrm{C}_{2} \mathrm{H}_{3} \mathrm{~S}^{+}$and $\mathrm{C}_{2} \mathrm{H}_{4} \mathrm{~S}^{+}$are formed in these reactions. An additional contribution to the $\mathrm{C}_{2} \mathrm{~S}_{2}{ }^{+}$ion results from reaction of $\mathrm{CS}^{+}$ with $\mathrm{CS}_{2}$. The reaction of $\mathrm{I}_{2}^{+}$with $\mathrm{CS}_{2}$ leads to the ion $\mathrm{CS}_{2} \mathrm{I}^{+}$. Reactions of excited molecular ions have also been found in benzonitrile, chlorobenzene, bromobenzene and iodobenzene. Ions of the $\mathrm{C}_{12}$ series such as $\mathrm{C}_{12} \mathrm{H}_{9} \mathrm{CN}^{+}, \mathrm{C}_{12} \mathrm{H}_{10}{ }^{+}$and $\mathrm{C}_{12} \mathrm{H}_{9}^{+}$are formed in these processes. In all cases, the appearance potential of the secondary ion is lower than the first dissociation limit of the molecular ion. It is therefore concluded that the excited ions are stable towards unimolecular decomposition. Repeller field studies show that they must be metastable towards decay by photon emission. In the case of aromatic ions this is explained by fast internal conversion of electronically excited ions into high vibrational levels of their electronic ground states. The form of the ionization efficiency curves of the secondary ions at high electron energies corresponds to what is expected if the excited precursors are formed in optically allowed transitions.
\end{abstract}

Most of the fundamental work on ion-molecule reactions during recent years has been carried out on processes which are initiated by ions in their ground states. Since the only reactions which can generally be observed in a mass spectrometer occur with high cross section and therefore with little activation energy only exothermic or thermo-neutral reactions have been expected to occur. However, as has recently been shown, endothermic reactions may be found if they are induced by ions carrying some excess energy. Several reactions induced by $\mathrm{I}_{2}{ }^{+}$carrying $1.3 \mathrm{eV}$ of excitation energy have been detected $^{1}$. Cermak and Herman ${ }^{2}$ have reported reactions of excited ions formed from simple molecules containing double or triple bonds such as $\mathrm{N}_{2}, \mathrm{O}_{2}, \mathrm{CS}_{2}$, $\mathrm{CO}, \mathrm{CO}_{2}$ and $\mathrm{SO}_{2}$. In the present paper several reactions of excited $\mathrm{CS}_{2}{ }^{+}$ions with water and iodine are described as well as a number of reactions of excited molecular ions of some aromatic compounds. In addition, some considerations about the lifetime and nature of the excited ions will be presented.

All experiments have been carried out with a Consolidated Electrodynamics Corporation Model 21-103 C mass spectrometer. The experimental details have already been reported ${ }^{1}$.

* This work is supported, in part, by the U.S. Atomic Energy Commission.

1 A. Henglein and G. A. Muccini, Z. Naturforschg. 15 a, 584 [1960].

2 V. Cermak and Z. Herman, J. Chim. Phys. 57, 717 [1960].

\section{Theoretical Considerations}

Four standard criteria have been generally applied in the investigation of ion-molecule reactions ${ }^{3,4}$.

1. Secondary ions are recognized by the proportionality of their intensity to the square of the pressure in the ionization chamber.

2. Comparisons of the appearance potential of the secondary ions with those of the primary ions lead to the identification of the precursor ion.

3 . The ratio of secondary to primary ion current $\left(i_{\mathrm{s}} / i_{\mathrm{p}}\right)$ is found to decrease with increasing repeller field strength.

4. Considerations of thermochemical data allow certain reactions which are endothermic in nature to be excluded from further consideration.

In the case of excited ions some complications are involved in criteria 2,3 and 4 which we now regard in some detail.

\section{Ionization efficiency curves and appearance potentials}

The ionization efficiency curve of a molecular ion is schematically shown by curve 1 in Fig. 1 . The

\footnotetext{
3 D. P. Stevenson and D. O. Schissler, J. Chem. Phys. 29, 282 [1958].

4 F. H. Field, J. L. Franklin and F. W. Lampe, J. Amer. Chem. Soc. 79, 2419 [1957].
} 
sharp change in slope at point a above the appearance potential $\mathrm{AP}(\mathrm{A})$ is due to the beginning of the excitation of a higher electronic state $B$ of the ion. The observed curve 1 is therefore the sum of

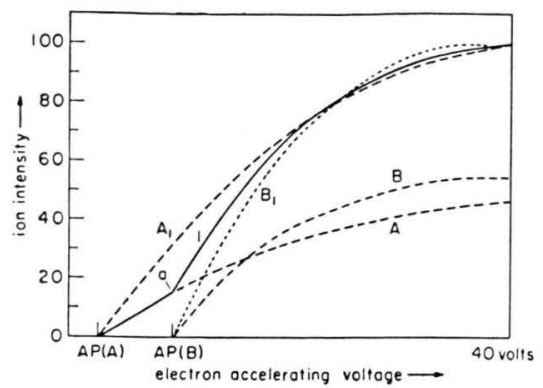

Fig. 1. Schematic analysis of the ionization efficiency curve of a molecular ion.

the corresponding curves $\mathrm{A}$ and $\mathrm{B}$ of the ground state and the excited state. In order to compare ionization efficiency curves we normalize them at 40 volts of electron accelerating voltage. If a reaction is induced by the excited state B only, the secondary ion will appear at $\mathrm{AP}(\mathrm{B})$ and its intensity will follow the ionization efficiency curve $B_{1}\left(B_{1}\right.$ is the normalized curve $B$ ). However, if only the ion in its ground state is able to initiate a reaction, the secondary ion will appear at $\mathrm{AP}(\mathrm{A})$ but its ionization efficiency curve $A_{1}$ will deviate from curve 1 especially at voltages only slightly above the appearance potential ( $A_{1}$ is the normalized curve $\left.A\right)$. The secondary ions described in this paper show ionization efficiency curves of the type represented by curve $B_{1}$. In the following paper a reaction in acrylonitrile will be reported where the precursor is only the molecular ion in its ground state.

The form of the ionization efficiency curve of a secondary ion at high electron accelerating voltages may give some information about the nature of the formation of the excited precursor by electron impact. The cross section $Q$ depends on the electron energy $T$ according to equation (1), if the transition from the ground state of the neutral molecule to the excited molecule ion is optically allowed.

$$
Q=\frac{4 \pi a_{0}{ }^{2} R^{2}}{T} \frac{t}{E} \ln c \cdot T
$$

( $a_{0}$ : Bohr-radius; $R$ : Rydberg constant; $f$ : oscillator strength of transition; $E$ : energy of excited

5 M. Burton and J. L. Magee, J. Phys. Chem. 56, 842 [1952].

${ }^{6}$ R. F. Pottie and W. H. Hamili, J. Phys. Chem. 63, 877 [1959]. state; $c$ : constant). The plot of $i_{\mathrm{s}} \cdot T$ versus $\log T$ will yield a straight line. Optically forbidden transitions will show a much stronger decrease in $Q$ with increasing $T$ than given by equation (1).

\section{Dependence of $i_{\S} / i_{\mathrm{p}}$ on the repeller field strength}

The activated complex which is formed in the reaction of a slow primary ion $\mathrm{P}^{+}$with a molecule M may often have different ways of decomposition to yield various secondary ion $\mathrm{S}^{+}$:

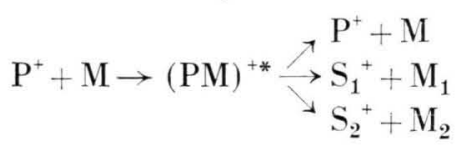

Each of these paths of dissociation is characterized by a unimolecular rate constant 5,6

$$
k_{i}=v\left(1-E_{i} / E\right)^{x-1}
$$

where $E$ is the total excitation energy of the complex and $E_{i}$ the energy required for dissociation along path $i, v$ is about $10^{-13} \sec ^{-1}, \alpha$ the number of degrees of vibrational freedom. According to the polarization theory ${ }^{7}$ of ion-molecule reactions, the cross section of the formation of the complex decreases with the reciprocal square root of the kinetic energy of the ion $\mathrm{P}^{+}$or repeller field strength $\varepsilon$, respectively.

$$
\sigma \propto \varepsilon^{-0.5} .
$$

In fact, a number of ion-molecule reactions have been observed in simple molecules where the total cross section $\sigma_{\mathrm{t}}$ was proportional ${ }^{3}$ to $\varepsilon^{-0.5}$. However, if several modes of dissociation of the intermediate complex can compete, the total cross section may depend on the repeller field strength according to

$$
\sigma_{\mathrm{t}} \propto \varepsilon^{\prime \prime}
$$

where $a$ is different from -0.5 . Part of the kinetic energy of the primary ion will appear as excitation energy of the complex. $E$ in equation (3) will therefore increase with increasing repeller field strength. As a result, the relative frequencies of the various paths of decomposition of the complex may change. The cross section of the formation of a particular secondary ion will decrease more strongly with increasing repeller field strength than expected from the $\sigma \sim \varepsilon^{-0.5}$ relation, if another path of decomposi-

\footnotetext{
7 G. Groumousis and D. P. Stevenson, J. Chem. Phys. 29, 294 [1958].
} 
tion becomes more frequent. Many ion-molecule reactions are already known, the cross sections of which depend on $\varepsilon$ by an exponent $a$ between -0.5 and $-1.0^{3,4,8}$. Our data presented in Fig. 10 show even higher negative values of $a$ for some reactions studied. At higher kinetic energies of the primary ion the most frequent product ion of the collision is probably the ion $\mathrm{P}^{+}$itself or its dissociation products. This is well known from studies of collision induced dissociation of ions ${ }^{9-11}$. At these higher ion energies the lifetime of the complex is shorter than the time required for distribution of the excitation energy in the various degrees of freedom of the complex; i. e. there is practically no real complex formation. Perhaps, this process is already competing with many ion-molecule reactions at lower ion energies *.

The current ratio $i_{\mathrm{s}} / i_{\mathrm{p}}$ is given by the relation

$$
i_{\mathrm{s}} / i_{\mathrm{p}}=\sigma_{\mathrm{t}(\varepsilon)} l c
$$

where $c$ is the concentration of gas molecules and $l$ is the path length of the primary ion in the ionization chamber. This path length is constant and is independent of the repeller field strength, if the lifetime of the primary ion is much longer than the time of its residence in the ionization chamber; i. e. $10^{-7}-10^{-6}$ seconds. However, if an excited primary ion is deactivated by either photon emission or dissociation within a much shorter time, it can initiate bi-molecular reactions only along a short part of its total path. The path length $l_{1}$ which it traverses in its excited state will be proportional to the repeller field strength. The current ratio now will become:

$$
i_{\mathrm{s}} / i_{\mathrm{p}}=\sigma_{\mathrm{t}(\varepsilon)} c l_{1(\varepsilon)} .
$$

Introduction of the dependences of $\sigma$ and $l_{1}$ on $\varepsilon$ leads to

$$
i_{\mathrm{s}} / i_{\mathrm{p}} \sim \varepsilon^{a} \cdot \varepsilon^{1} \sim \varepsilon^{1+a} .
$$

If the exponent $a$ lies in the range of -0.5 to -1.0 , the current ratio will now increase or at least be constant with increasing repeller field strength.

8 F. W. Lampe, F. H. Field and J. L. Franklin, J. Amer. Chem. Soc. 79, 6132 [1957].

9 J. Mattauch and H. Lichtblau, Phys. Z. 40, 16 [1939].

10 A. Henglein, Z. Naturforschg. 7 a, 165 [1952].

11 C. E. Melton and H. M. Rosenstock, J. Chem. Phys. 26, 568 [1957].

* If dissociation of the complex into $\mathrm{P}^{+}+\mathrm{M}$ is negligible,

\section{Experimental Results}

The ion-molecule reactions observed in this work are listed in Table 1. Reaction I has been used as a standard reaction to calculate relative cross sections. The current ratios $i_{\mathrm{s}} / i_{\mathrm{p}}$ of this table have been measured at a pressure of $500 \mu$ in the reservoir of the gas inlet system. These observations were carried out at electron accelerating voltages of 40 volts and a repeller field strength of 3.84 volts $/ \mathrm{cm}$. The ion current of all ions reported in this paper as secondary ions have been found to be proportional to the square of the pressure.

Fig. 2-9 show the ionization efficiency curves for the secondary ions and a number of primary ions. All curves have been normalized at 40 volts. The plots show the ionization efficiency curves in the range from 9 to 40 volts and in some cases also from 40 to 170 volts. All measurements of the repeller field dependence of the ratio $i_{\mathrm{s}} / i_{\mathrm{p}}$ are compiled in Fig. 10.

\section{Carbon disulfide}

Cermak and Herman ${ }^{2}$ have already interpreted the formation of the secondary ions $\mathrm{CS}_{3}{ }^{+}, \mathrm{C}_{2} \mathrm{~S}_{2}{ }^{+}$and $\mathrm{C}_{2} \mathrm{~S}_{3}{ }^{+}$as products of reactions of the excited carbon disulfide ion. The present studies confirm this conclusion. A comparison of the ionization efficiency curves of the secondary ions given in Fig. 3 with those of the primary ions in Fig. 2 clearly shows that

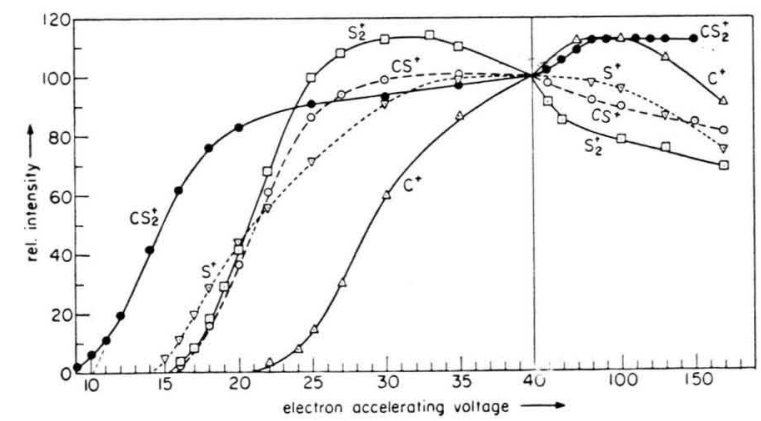

Fig. 2. Ionization efficiency curves of primary ions in carbon disulfide.

there should exist as many ion-molecule reactions of $|a|<0.5$

than reactions of $|a|>0.5$. However, reactions for which the exponent $a$ has a lower negative value than 0.5 have never been observed. It is, therefore, concluded that the formation of $\mathrm{P}^{+}$(or its dissociation products) is an important competing process the relative frequency of which much stronger increases with increasing $\varepsilon$ than that of any other secondary ion. 


\begin{tabular}{|c|c|c|c|c|}
\hline No. & $\begin{array}{l}\text { Secondary } \\
\text { ion }\end{array}$ & Mode of Formation & $i_{\mathrm{S}} / i_{\mathrm{p}}^{\mathrm{a}}$ & $\begin{array}{l}\text { relative } \\
\text { cross }^{b} \\
\text { section }\end{array}$ \\
\hline I & $\mathrm{H}_{3} \mathrm{O}^{+}$ & $\begin{array}{c}\mathrm{H}_{2} \mathrm{O}^{+}+\mathrm{H}_{2} \mathrm{O} \rightarrow \underset{\mathrm{H}_{3} \mathrm{O}^{+}+}{\text {water }} \mathrm{OH} \\
\text { carbon disulfide }\end{array}$ & $2.4 \cdot 10^{-2}$ & 1 \\
\hline II & $\mathrm{CS}_{3}^{+}$ & $\mathrm{CS}_{2}+*+\mathrm{CS}_{2} \rightarrow \mathrm{CS}_{3}^{+}+\mathrm{CS}$ & $1.1 \cdot 10^{-3}$ & 0.044 \\
\hline III & $\mathrm{C}_{2} \mathrm{~S}_{2}^{+}$ & $\mathrm{CS}_{2}^{+*}+\mathrm{CS}_{2} \rightarrow \mathrm{C}_{2} \mathrm{~S}_{2}++\mathrm{S}_{2}$ & $6.0 \cdot 10^{-5}$ & 0.0025 \\
\hline IV & $\mathrm{C}_{2} \mathrm{~S}_{2}^{+}$ & $\mathrm{CS}^{+}+\mathrm{CS}_{2} \rightarrow \mathrm{C}_{2} \mathrm{~S}_{2}^{+}+\mathrm{S}$ & $7.2 \cdot 10^{-4}$ & 0.03 \\
\hline V & $\mathrm{C}_{2} \mathrm{~S}_{3}^{+}$ & $\mathrm{CS}_{2}{ }^{+*}+\mathrm{CS}_{2} \rightarrow \mathrm{C}_{2} \mathrm{~S}_{3}++\mathrm{S}$ & $6.0 \cdot 10^{-5}$ & 0.0025 \\
\hline VI & $\mathrm{H}_{2} \mathrm{OS}^{+}$ & $\begin{array}{c}\text { carbon disulfide-water }{ }^{\mathrm{c}} \\
\mathrm{CS}_{2}{ }^{+*}+\mathrm{H}_{2} \mathrm{O} \rightarrow \mathrm{H}_{2} \mathrm{OS}^{+}+\mathrm{CS} \\
\text { carbon disulfide-iodine }\end{array}$ & $1.3 \cdot 10^{-4}$ & 0.011 \\
\hline VII & $\mathrm{CS}_{2} \mathrm{I}^{+}$ & $\mathrm{I}_{2}^{+}+\mathrm{CS}_{2} \rightarrow \mathrm{CS}_{2} \mathrm{I}^{+}+\mathrm{I}$ & $5.7 \cdot 10^{-3}$ & 0.42 \\
\hline VIII & $\mathrm{CSI}^{+}$ & $\mathrm{CS}_{2}{ }^{+*}+\mathrm{I}_{2} \rightarrow \mathrm{CSI}^{+}+\mathrm{SI}$ & $4.2 \cdot 10^{-4}$ & 0.036 \\
\hline IX & $\mathrm{SI}^{+}$ & $\mathrm{CS}_{2}{ }^{+*}+\mathrm{I}_{2} \rightarrow \mathrm{SI}^{+}+\underset{\mathrm{CSI}}{\mathrm{C}}$ & $1.2 \cdot 10^{-3}$ & 0.10 \\
\hline $\mathrm{X}$ & $\mathrm{C}_{12} \mathrm{H}_{9} \mathrm{CN}^{+}$ & $\begin{array}{c}\mathrm{C}_{6} \mathrm{H}_{5} \mathrm{CN}^{+*}+\mathrm{C}_{6} \mathrm{H}_{5} \mathrm{CN} \rightarrow \mathrm{C}_{12} \mathrm{H}_{9} \mathrm{CN}^{-}+\mathrm{HCN} \\
\text { chlorobenzene }\end{array}$ & $3.2 \cdot 10^{-3}$ & 0.13 \\
\hline XI & $\mathrm{C}_{12} \mathrm{H}_{9}{ }^{+}$ & $\begin{array}{c}\mathrm{C}_{6} \mathrm{H}_{5} \mathrm{Cl}^{+*}+\mathrm{C}_{6} \mathrm{H}_{5} \mathrm{Cl} \underset{\text { bromobenzene }}{\rightarrow} \mathrm{C}_{12} \mathrm{H}_{9}^{+}+\mathrm{HCl}+\mathrm{Cl} \\
\end{array}$ & $2.7 \cdot 10^{-3}$ & 0.11 \\
\hline XII & $\mathrm{C}_{12} \mathrm{H}_{10}^{+}$ & $\begin{array}{c}\mathrm{C}_{6} \mathrm{H}_{5} \mathrm{Br}^{+*}+\mathrm{C}_{6} \mathrm{H}_{5} \mathrm{Br} \rightarrow \mathrm{C}_{12} \mathrm{H}_{10}+ \\
\text { iodobenzene }\end{array}$ & $6.3 \cdot 10^{-3}$ & 0.26 \\
\hline XIII & $\mathrm{C}_{12} \mathrm{H}_{10^{+}}$ & $\mathrm{C}_{6} \mathrm{H}_{5} \mathrm{I}^{+*}+\mathrm{C}_{6} \mathrm{H}_{5} \mathrm{I} \rightarrow \mathrm{C}_{12} \mathrm{H}_{10^{+}}+\mathrm{I}_{2}$ & $1.6 \cdot 10^{-2}$ & 0.70 \\
\hline
\end{tabular}

${ }^{\text {a }}$ at $500 \mu$ of pressure in the reservoir of the gas inlet system.

b reaction I was chosen as reference reaction.

c each component had a pressure of $250 \mu$ in the reservoir of the gas inlet system.

Table 1. List of ion-molecule reactions.

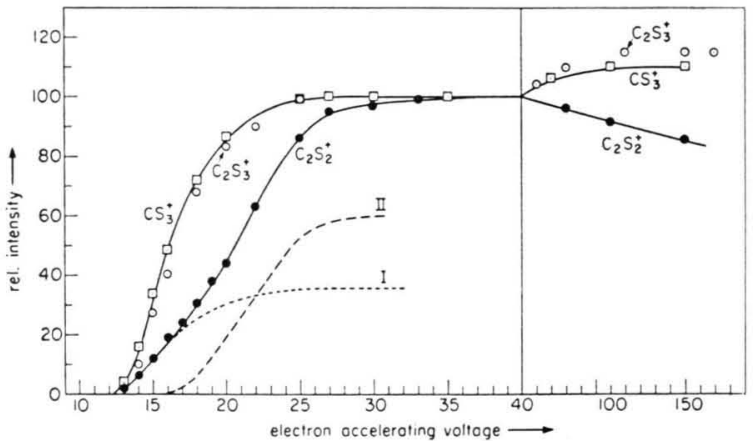

Fig. 3. Ionization efficiency curves of secondary ions in carbon disulfide.

only an excited parent ion appearing at $13.0 \pm 0.3$ volts can be the precursor of the secondary ions. The secondary ions have the same appearance potential and therefore the same precursor. The appearance potential of 13.3 volts agrees well with that of $13.60 \pm 0.19$ which has been attributed by Collin ${ }^{12}$ to the ${ }^{2} \Pi_{3 / 2 \mu}$ state of the $\mathrm{CS}_{2}{ }^{+}$ion.

Although the ionization efficiency curves for $\mathrm{CS}_{3}{ }^{+}$and $\mathrm{C}_{2} \mathrm{~S}_{3}{ }^{+}$are essentially identical, the curve of the $\mathrm{C}_{2} \mathrm{~S}_{2}^{+}$ion rises less steeply just above the

12 J. Collin, J. Chim. Phys. 57, 424 [1960]. appearance potential. The slope of the $\mathrm{C}_{2} \mathrm{~S}_{2}{ }^{+}$curve then increases at higher voltages. It is concluded that $\mathrm{C}_{2} \mathrm{~S}_{2}{ }^{+}$is formed at higher voltages not only by reaction III but also by an additional process.

If it is assumed that $\mathrm{C}_{2} \mathrm{~S}_{2}{ }^{+}$is exclusively formed by $\mathrm{CS}_{2}^{+*}$ between 13.3 and 15.0 volts this range of the $\mathrm{C}_{2} \mathrm{~S}_{2}{ }^{+}$curve can be extrapolated to higher voltages using the form of the $\mathrm{CS}_{3}{ }^{+}$curve. Curve 1 has been obtained this way. It gives the contribution of reaction III to the formation of $\mathrm{C}_{2} \mathrm{~S}_{2}{ }^{+}$. If curve 1 is subtracted from the $\mathrm{C}_{2} \mathrm{~S}_{2}^{+}$curve, curve II is obtained. This additional contribution has essentially the same form as the ionization efficiency curve of the primary $\mathrm{CS}^{+}$ion which is the only carbon containing ion with an appearance potential of about 16 volts. We therefore attribute this part of the formation of $\mathrm{C}_{2} \mathrm{~S}_{2}{ }^{+}$to reaction IV (Table 1) of this ion.

The excited state of the $\mathrm{CS}_{2}{ }^{+}$ion is able to undergo many reactions with other molecules. Fig. 4 and 5 show that the ions $\mathrm{H}_{2} \mathrm{OS}^{+}$, $\mathrm{CSI}^{+}$and $\mathrm{SI}^{+}$are formed in mixtures of carbondisulfide with water and iodine, respectively. The curves in these figures make clear that no other ion than $\mathrm{CS}_{2}^{+*}$ can be the precursor of those secondary ions. $\mathrm{CS}_{2} \mathrm{I}^{+}$has been observed too. Since its ionization efficiency curve is 


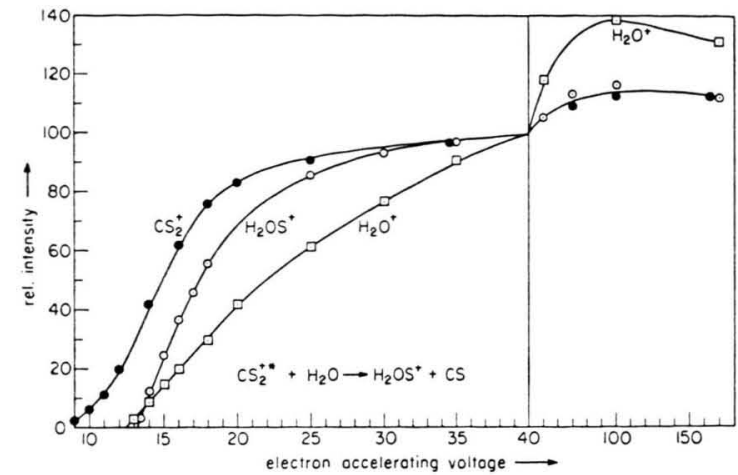

Fig. 4. Ionization efficiency curves of $\mathrm{H}_{2} \mathrm{OS}^{+}$and $\mathrm{H}_{2} \mathrm{O}^{+}$in l: 1 water-carbon disulfide.

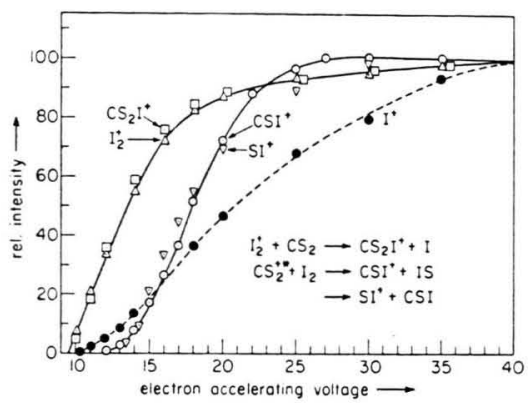

Fig. 5. Ionization efficiency curves of ions in $1: 1$ iodinecarbon disulfide.

identical with that of $\mathrm{I}_{2}^{+}$, reaction VII in Table 1 has been formulated.

Some preliminary experiments have been carried out with mixtures of carbondisulfide and hydrocarbons. The secondary ions $\mathrm{C}_{2} \mathrm{H}_{3} \mathrm{~S}^{+}$and $\mathrm{C}_{2} \mathrm{H}_{4} \mathrm{~S}^{+}$ have been observed in mixture with ethylene. The appearance potentials of 13.4 and 12.8 of these ions again are much higher than those of the parent ions in this mixture $\left[\mathrm{AP}\left(\mathrm{CS}_{2}^{+}\right): 10.1 ; \mathrm{AP}\left(\mathrm{C}_{2} \mathrm{H}_{4}\right): 10.5\right.$ volts]. Either an excited molecular ion of $\mathrm{CS}_{2}$ or $\mathrm{C}_{2} \mathrm{H}_{4}$ must therefore be the precursor.

\section{Aromatic compounds}

A number of ion-molecule reactions have been found in benzonitrile and the phenyl halides and are listed in Table 1. That the secondary ions observed result from the reactions of excited molecular ions can be readily determined in these compounds for two reasons. First, the secondary ions have rather high intensities. Second, they belong to the $\mathrm{C}_{12}$ series such as $\mathrm{C}_{12} \mathrm{H}_{10}{ }^{+}, \mathrm{C}_{12} \mathrm{H}_{9}{ }^{+}$and $\mathrm{C}_{12} \mathrm{H}_{9} \mathrm{CN}^{+}$. The mass spectra of these aromatic compounds contain only a small number of primary $C_{6}$ ions which

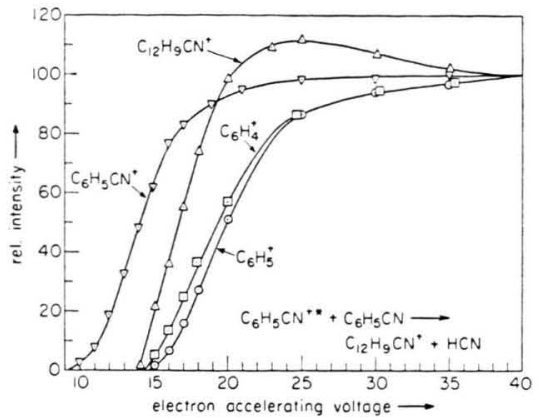

Fig. 6. Ionization efficiency curves of ions in benzonitrile.

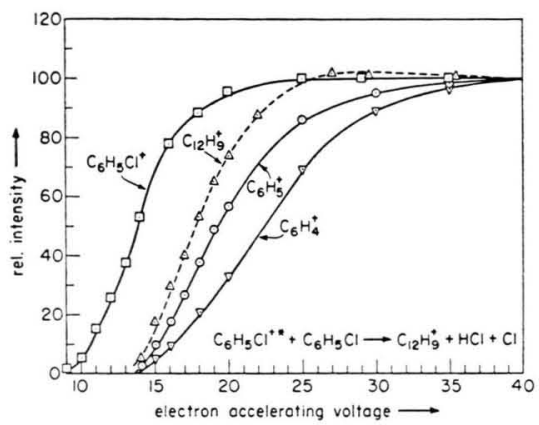

Fig. 7. Ionization efficiency curves of ions in chlorobenzene.

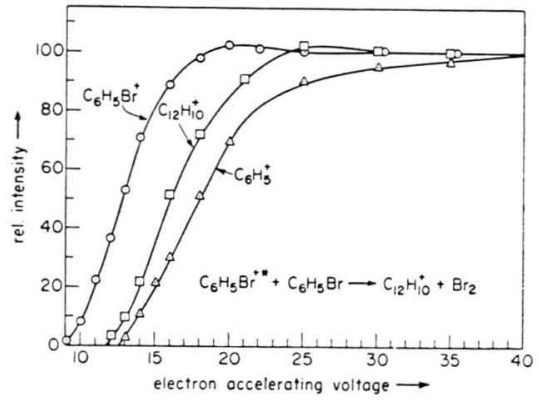

Fig. 8. Ionization efficiency curves of ions in bromobenzene.

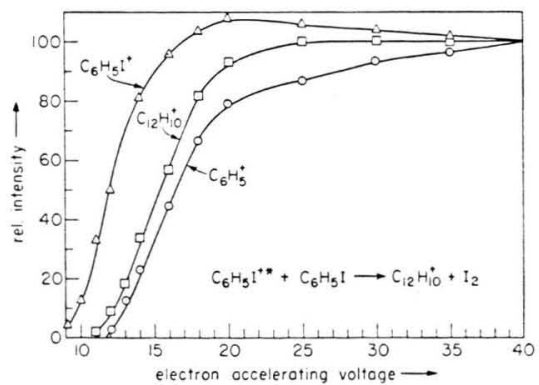

Fig. 9. Ionization efficiency curves of ions in iodobenzene.

have sufficient intensity to be possible precursor of secondary ions of the $\mathrm{C}_{12}$-series. Only $\mathrm{C}_{6} \mathrm{H}_{5}{ }^{+}$and, in some cases, $\mathrm{C}_{6} \mathrm{H}_{4}{ }^{+}$have to be regarded besides the 
parent ion. The ionization efficiency curves of those ions are shown together with those of the secondary ions in Fig. 6-9. It can be seen that the secondary ion always appears below the first dissociation limit of the parent ion; i. e. below $\operatorname{AP}\left(\mathrm{C}_{6} \mathrm{H}_{5}{ }^{+}\right)$and AP $\left(\mathrm{C}_{6} \mathrm{H}_{4}{ }^{+}\right)$, but much higher than the AP of the parent ion. It is again concluded that excited states of the molecular ions are the precursors.

\section{Nature and life time of the excited ions}

Excited ions may be unstable towards either dissociation or photon emission. Spontaneous dissociations of metastable ions are well known in mass spectrometry ${ }^{13,14}$. The daughter ions of such metastable transitions generally have the same appearance potentials as the same ions produced as primary ions in the ionization chamber. Metastable molecular ions of the aromatic compounds studied here have been observed in their mass spectra. However, it does not appear that metastable ions which are capable of unimolecular decomposition are also the initiators of our bimolecular reactions since our secondary ions always appear below the first dissociation limit of the parent ion. For example, in carbon disulfide $\mathrm{CS}^{+}$and $\mathrm{S}^{+}$appear at 15.7 and 14.3 volts, respectively; i. e. above the 13.3 volts of the excited state of $\mathrm{CS}_{2}{ }^{+}$. Similarly it was observed in the previous studies of reactions of excited $\mathrm{I}_{2}{ }^{+}$ions that the secondary ions appear about 1 volt below the dissociation of $\mathrm{I}_{2}^{+}$into $\mathrm{I}^{+}+\mathrm{I}$ (ref. ${ }^{1}$ ). It must therefore be concluded that the excited ions, which initiate bimolecular reactions, are stable with respect to dissociation.

The high relative cross sections in Table 1 already indicate that the excited ions do not decay by photon emission within about $10^{-8}$ sec., i. e. the time for optically allowed transitions. This is especially evident for the primary ions in the aromatic compounds where reaction cross sections as nearly as large as that of the water reaction have been observed. As already mentioned excited ions of short lifetime will pass only a very short path $l_{1}$ in the ionization chamber along which they have a chance to meet a gas molecule. The current ratio $i_{\mathrm{s}} / i_{\mathrm{p}}$ of their reactions should therefore be smaller by about two orders of magnitude than that of the standard reaction. It must be remembered here that Table 1 gives only minimum values of $i_{\mathrm{S}} / i_{\mathrm{p}}$ and of relative

13 J. A. Hipple, Phys. Rev. 71, 594 [1947].

14 See for complete reference F. H. Field and J. L. Franklin, cross sections of excited ion-reactions since only part of all primary parent ions formed by electron impact will have excess energy.

The ratio $i_{\mathrm{s}} / i_{\mathrm{p}}$ of most of the reactions studied depends on the repeller field strength according to equation (5). The logarithmic plots in Fig. 10

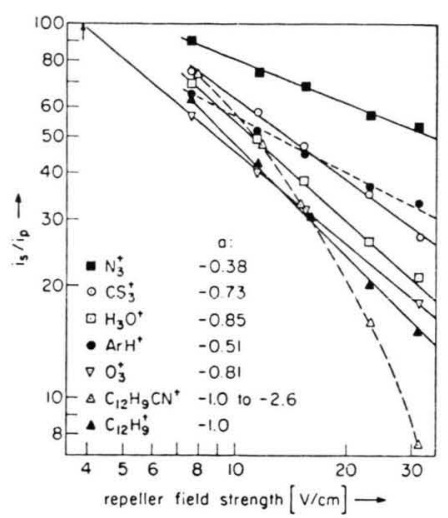

Fig. 10. Ratio $i_{\mathrm{s}} / i_{\mathrm{p}}$ as function of repeller strength. The ratio at 3.84 volts $/ \mathrm{cm}$ has been normalized to 100 . $a$ is the exponent in equation (5).

generally yield straight lines for repeller field strengths above 5 volts $/ \mathrm{cm}$. The data of the excited ion-molecule reactions $\mathrm{I}_{2}^{+*}+\mathrm{H}_{2} \mathrm{O} \rightarrow \mathrm{H}_{2} \mathrm{OI}^{+}+\mathrm{I}^{1}$, $\mathrm{N}_{2}^{+*}+\mathrm{N}_{2} \rightarrow \mathrm{N}_{3}^{+}+\mathrm{N}^{2}, \quad \mathrm{O}_{2}^{+*}+\mathrm{O}_{2} \rightarrow \mathrm{O}_{3}^{+}+\mathrm{O}^{2}$ and of two reference reactions $\mathrm{H}_{2} \mathrm{O}^{+}+\mathrm{H}_{2} \mathrm{O} \rightarrow \mathrm{H}_{3} \mathrm{O}^{+}+\mathrm{OH}$ and $\mathrm{A}^{+}+\mathrm{H}_{2} \rightarrow \mathrm{AH}^{+}+\mathrm{H}$ are included in the figure. The slope of the latter reaction was found to be equal to -0.51 which agrees with the findings of Stevenson $^{3}$. A value of -0.85 was observed for the reaction in water which again agrees fairly well with the value of -0.73 calculated from the data of LAMpe et al. ${ }^{8}$. The exponent $a$ varies over a wide range for the other reactions. It becomes even higher than -1.0 in some cases. Reaction X, for example, is extremely dependent on the repeller field strength. The corresponding curve in Fig. 10 shows an increase in slope with increasing repeller field strength. This is attributed to some competing reactions of the activated complex as mentioned above.

An increase of $i_{\mathrm{s}} / i_{\mathrm{p}}$ with increasing $\varepsilon$ (positive $a$ ) as expected for reactions of short living excited ions. has never been observed. The reaction in nitrogen showed a smaller negative exponent $a$ than 0.5 . The value of -0.38 found here is the only indication that there might be a short living precursor in this

Electron Impact Phenomena, Academic Press Inc. Publ., New York 1957. 
reaction. If there is not some hitherto unknown influence of the repeller field strength on the ratio $i_{\mathrm{s}} / i_{\mathrm{p}}$ of excited ion-reactions, it must be concluded that the lifetimes of the precursors of our reactions are longer than $10^{-6}$ sec.

The stability of the excited aromatic ions may be explained by fast internal conversion from the electronically excited ion to high vibrational levels of its electronic ground state. Internal conversion is known to be very efficient in deactivating higher electronic states in polyatomic neutral molecules ${ }^{15}$. Because of the large energy difference between the lowest excited state and the ground state, internal conversion generally stops at the lowest excited state which further decays by photon emission. In the case of aromatic ions, however, the spacing between

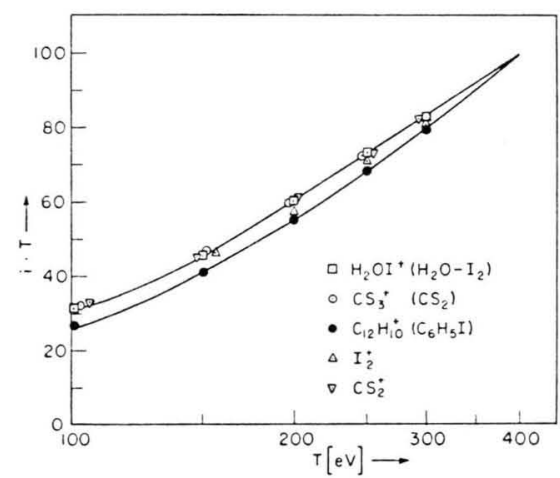

Fig. 11. Plot of the product $i T$ versus $\log T$. The product $i T$ at $T=400 \mathrm{eV}$ has been made equal to 100 . ( $i$ : ion current; $T$ : kinetic energy of bombarding electrons).

15 M. Kasha and S. P. McGlynn, Ann. Rev. Phys. Chem. 7, 403 [1956].

${ }^{16}$ R.E.Fox and W.M. Нıскам, J. Chem. Phys. 22, 2059 [1954]. the levels always seems to be much smaller. This may be concluded from the experiments of Fox and Нгскам ${ }^{16}$ on ionized benzene, in which four excited states below the first dissociation limit were found. It seems therefore plausible that internal conversion of excited ions will lead to the ground state of the ion. According to this explanation, the ions do not enter their bimolecular reactions with neutral molecules in the same electronic states in which they were formed by electron impact. A similar explanation may be possible for the stability of the excited iodine ion ${ }^{1}$. Internal conversion again may be favored by the large number of excited states just above the appearance potential of the ion ${ }^{17}$. No general explanation can be given for the other ions consisting of a small number of atoms. Perhaps some of these excited ions decay by light emission to give a lower metastable state of long lifetime.

Some plots of the product $i T$ versus $\log T$ are shown by Fig. 11. The diagram contains data for some secondary ions as well as for the primary ions $\mathrm{I}_{2}^{+}$and $\mathrm{CS}_{2}^{+}$. Although equation (1) is only valid at electron energies of several hundred $\mathrm{eV}$ reasonably straight lines result from the data in Fig. 11 . The deviations at the lower energies in Fig. 11 are due to the failure of the relationship in this range. Apparently all of the excited ions described are formed in optically allowed transitions.

The author wishes to thank Mr. G. K. Buzzard for his assistance in carrying out the experiments reported here.

17 J. D. Morrison, H. Hurzeler, M. G. Inghram and H. E. Stanton, J. Chem. Phys. 33, 821 [1960]. 